\title{
Why Conduct Research into Psychosexual Care?
}

Psychosexual concerns post robotic prostatectomy is critically important as there is a significant unaddressed gap in care [1]. The NHS Hospital involved in this study has a relevant identifiable cohort of patients, able to be asked to participate. In order to develop a psychosexual prostate cancer intervention and identify the most pressing research questions, a systematic review was conducted. The research question was based on systematic review findings. Psychosexual concern post-surgery was highlighted as a significant unaddressed need within the systematic review.

Identification of patient needs and implementation of appropriate psychosexual care post robotic prostatectomy is critically important because of the unaddressed gap in care. In order to develop a psychosexual pathway (model of care) for men with prostate cancer post robotic surgery, patient views and active participation in developing the pathway are paramount and will be key to this study.

The theoretical model underpinning the research approach is self-efficacy [2]. Patients are control of their own healthcare and are the most appropriately based person to identify their own needs and concerns. Patients need to be empowered to express their concerns. Healthcare professionals also need their awareness of these needs enhanced.

This research is central to furthering psychosexual care for patients post radical prostatectomy and if successful, developing the foundation for guidance on psychosexual care post radical robotic prostatectomy. The first step in this process is to conduct a systematic review.

\section{References}

1. Maddams J, Brewster D, Gavin A, Steward J, Elliott J, Utley M, Moller H. Cancer prevalence in the United Kingdom: estimates for 2008. Br J Cancer. 2009;101:541-7.

2. Heldenbrand SD, Turnbow LE, Payakachat N. Patient self-efficacy and satisfaction after medication education following solid organ transplantation. Pharmacotherapy. 2010;30(10):425e. 